\title{
THE MANAGEMENT OF CHRONIC ARTHRITIS AND OTHER RHEUMATIC DISEASES AMONG SOLDIERS OF THE UNITED STATES ARMY*
}

\author{
BY \\ PHILIP S. HENCH, M. C. (Colonel, Army of the U.S.) $\dagger$ \\ and
}

EDWARD W. BOLAND, M. C. (Major, Army of the U.S.)

During the First World War about 93,000 American soldiers developed some sort of " rheumatism." 1 Four common rheumatic diseasesrheumatoid arthritis, rheumatic fever, osteo-arthritis, and muscular rheumatism-accounted for about $80 \%$ of these cases (Table 1). The subsequent

Table 1.-INCidence of Certain Diseases in the United States Army, First World War (April 1, 1917, to Dec. 31, 1919)

Total of Mean Annual Strengths for the War Period-4,128,479 Soldiers

\begin{tabular}{|c|c|c|c|}
\hline Condition & $\begin{array}{l}\text { Total } \\
\text { Cases }\end{array}$ & Percentage & $\begin{array}{l}\text { Rates per } \\
1,000 \text { soldiers }\end{array}$ \\
\hline $\begin{array}{l}\text { Arthritis (rheumatoid and } \\
\text { osteo-arthritis). }\end{array}$ & 33,613 & 36 & $8 \cdot 14$ \\
\hline $\begin{array}{l}\text { Acute articular rheumatism } \\
\text { (rheumatic fever). }\end{array}$ & 24,770 & 27 & 6.00 \\
\hline "Muscular rheumatism" & 12,093 & 13 & $2 \cdot 93$ \\
\hline Gonorrhoeal arthrit is & 7.895 & 9 & 1.91 \\
\hline "Myositis" $§$ & 4,135 & 4 & 1.00 \\
\hline "Synovitis" § $\quad$. & 3,665 & 4 & .87 \\
\hline "Tenosynovitis" $\S$ & 2,671 & 3 & .65 \\
\hline "Ankylosis of joints" $\$$. & 1,907 & 2 & .46 \\
\hline $\begin{array}{l}\text { " Other diseases of joints " } \\
\text { (non-traumatic). }\end{array}$ & 1,614 & 2 & .39 \\
\hline Tuberculous arthrit is & 188 & - & .05 \\
\hline Gouty arthritis $\quad$. & 82 & - & .02 \\
\hline Total & 92,633 & 100 & $22 \cdot 43$ \\
\hline
\end{tabular}

cost to the government of these 92,633 cases of rheumatism has never been estimated; it must have been very great. In 1931, thirteen years after the war, the Veterans' Administration was paying over $\$ 10,000,000$ a year in disability compensations to about 35,000 ex-Servicemen with " arthritis," "2 and

* From the Rheumatism Centre, Army and Navy General Hospital, Hot Springs, Arkansas.

+ Director of the Rheumatism Centre and Chief of the Medical Service (now returned to the Mayo Clinic, Rochester, Minnesota).

$\ddagger$ Chief of the Section on Rheumatic Diseases (now returned to Los Angeles, California).

In addition to the 24,770 cases of acute articular rheumatism (rheumatic fever), there were 17,372 cases of "valvular heart disease," the great majority of which were probably rheumatic in origin.

$\S$ These conditions were not fully defined in the original reference; the terms are those used in the Manual of the International List of Causes of Death, Second Revision, Paris, 1909; Washington, D.C., Government Printing Office, 1913. in 1943-twenty-five years after the war-the Veterans' Administration was expending annually $\$ 2,500,000$ in pensions alone to soldiers of World War I with rheumatic heart disease. ${ }^{3}$

\section{Need for Rheumatism Centres}

During the First World War no special rheumatism centre was officially established by the War Department. However, Major Ralph Pemberton and his associates were afforded the opportunity of studying carefully at United States General Hospital Number 9, Lakewood, New Jersey, 400 cases of chronic arthritis among soldiers." "Although General Hospital Number 9 was never designated as a 'centre,' it functioned as one." 5

During World War I the mean strength of the American Army over a period of two and threequarter years (33 months: April 1, 1917, to December 31 , 1919) was $4,128,479$. Thus, during every month of that war an average of 2,807 soldiers developed rheumatism. If the incidence rate for "rheumatic diseases" among soldiers during that war $(22.4$ cases per 1,000 soldiers $)$ were maintained during this second world conflict, the War Department could expect that, out of an army of $8,000,000$ soldiers, there would develop within the first two and three-quarter years of this war (namely, between December, 1941, and August, 1944, inclusive) about 180,000 cases of rheumatism-an average of about 5,454 cases during every month of the war. Of these 180,000 cases, about 64,000 cases would be of chronic rheumatoid arthritis or of osteo-arthritis. (The figures for this war are not yet available.) To prepare for such a possibility, the Surgeon-General and his Associates, with the co-operation of the American Rheumatism Association, took, in the fall of 1942 , the first tentative steps toward the subsequent establishment of one or more rheumatism centres for the Army if or when the need materialized. ${ }^{6}$ To date the need has been such that five rheumatism centres have been established-two for patients with chronic rheumatic diseases, and three for patients with rheumatic fever. $T$

Three rheumatism centres were recently established for the join Services (Navy, Army, Air Force) of the Canadian Government: one at St. Thomas. Ontario, opened in June, 1945; others at Winnipes and at Nanaimo, B.C., opened in April, 1945. 


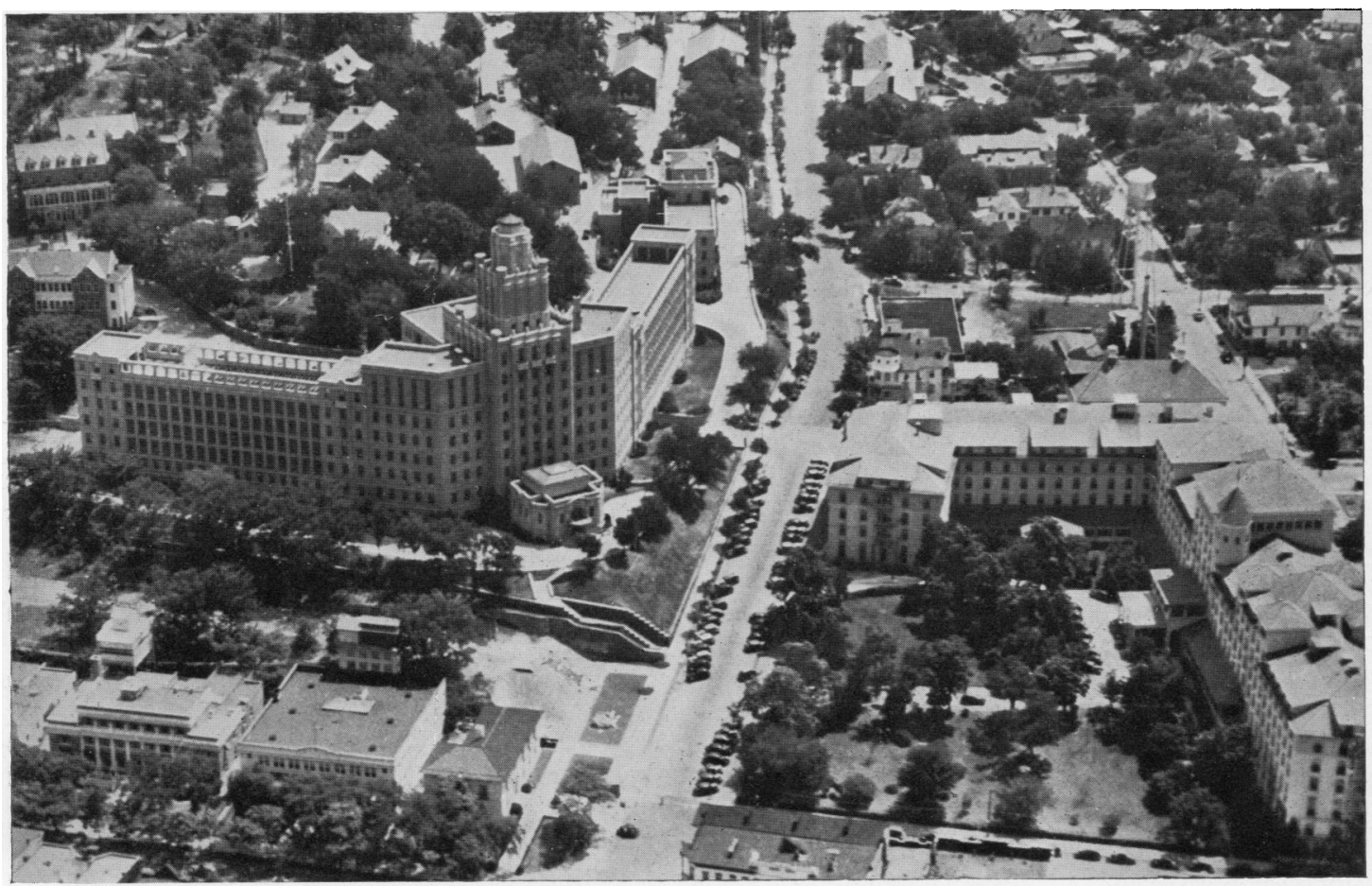

The Rheumatism Centre of the United States Army at the Army and Navy General Hospital ; the main building (left) is now connected with the Eastman Annex (right).

\section{Purposes of a Centre}

The majority of soldiers who develop rheumatism need not be transferred to special centres. Patients with transient muscular rheumatism, mild rheumatic fever without carditis, or acute traumatic or specific infectious arthritis can be handled effectively in the adjacent station or regional hospital. Rheumatism centres are designed for the care of difficult or progressive cases, or for diagnostic problems. ${ }^{7}$

The chief aims of a rheumatism centre are these:

1. Accurate diagnosis.-To provide a diagnostic centre where difficult cases can be studied by special methods and by medical officers with a special knowledge of rheumatic diseases.

2. Intensive treatment.-To provide special facilities for the treatment of the more severe or progressive cases.

3. Prompt disposition.-To accomplish as great a reduction in hospitalization-time as is consistent with adequate treatment.

4. Increased salvage.-To restore to duty, if possible, more men with " cured " or " arrested " disease.

5. Rehabilitation.-To educate and rehabilitate for civilian life those whose disability necessitates discharge from the Army.

6. Application of newer advances in treatment.

7. Appropriate clinical studies of patients while under treatment.

8. Long-range economy.-An incidental, but important aim is to reduce the costly need for disability pensions and prolonged hospitalization in Veterans' Facilities.

Centre at the Army and Navy General Hospital

On Dec. 17, 1943, the Surgeon-General designated the Army and Navy General Hospital as the first centre for the diagnosis and treatment of rheumatic diseases. ${ }^{8}$ This hospital, the Army's oldest general hospital, was chosen because of its past history and excellent facilities. Because of the adjacent hot springs, this hospital has, since 1887 , been a mecca for the rheumatic personnel of the Army. In 1933 the old main hospital building was demolished and replaced by a large new building, and in 1943 an adjacent large hotel was acquired, renovated, and connected to the main building, thus creating a capacity of 1,342 hospital beds with an additional 383 beds for patients being reconditioned (total 1,725 beds).

A proper knowledge of rheumatic diseases demands familiarity with all phases of general medicine. The productive record of American and European hospitals which have been devoted exclusively to the study of rheumatic diseases has often been disappointing. Rheumatism clinics and services in civilian hospitals maintain their vitality by, and derive much of their inspiration from, their close association with the other clinical and laboratory departments. Therefore, one of the chief advantages of this rheumatism centre is its placement in a large general hospital with its varied medical and surgical specialties. Thus the rheumatic patient commands the services of specialists in many fields.

The rapid growth of the centre is shown by the daily census of the section on rheumatic diseases, which increased from 56 patients present on a given day in January, 1944, to 704 patients actually present on a given day in October, 1944. During the year 
1944, 3,105 "rheumatic patients" were admitted, and, between January and June, 1945, inclusive, 2,210 additional "rheumatic patients" were admitted-a total of 5,315 in 18 months. Many of the patients have been received from various camps throughout the country, but during recent months most of the patients have come from overseas hospitals. The majority have come by boat from the South Pacific or from the European theatre of operations, but many have come via the ambulance planes of the Air Transport Command. The speed of evacuation of certain rheumatic patients from overseas has often been startling; some have arrived here by plane 4 to 6 days after leaving South Pacific hospitals (e.g. 4 days from Saipan to Hot Springs); others have arrived within 3 to 7 days from England, Italy, or France (e.g. from Paris to Hot Springs in 3 days). Such promptness in evacuating rheumatic soldiers from overseas to hospitals equipped especially for their needs fosters a fine morale among the soldiers and their anxious relatives. A proportionate promptness in the subsequent diagnosis and disposition (consistent with adequate treatment) has done much to maintain their morale.

The Centre at Ashburn General Hospital

Because the flow of rheumatic patients to the first centre became excessive, a second centre for chronic rheumatic diseases was established on Aug. 25, 1944, at Ashburn General Hospital, McKinney, Texas. ${ }^{9}$ During its first eight months the Section on Rheumatic Diseases at that hospital admitted about 2,200 patients. ${ }^{10}$

\section{Centres for Patients with Rheumatic Fever}

Also on Aug. 25, 1944, the Súrgeon-General established three centres for the care of soldiers with rheumatic fever: ${ }^{9}$ at Birmingham General Hospital, Van Nuys, California; at Foster General Hospital, Jackson, Mississippi; at Torney General Hospital, Palm Springs, California. Within the first eight months a total of about 900 patients with rheumatic fever were admitted to these three hospitals, ${ }^{11}$ most of the patients having been transported thereto by air as soon as possible after the acute phase of the disease began to subside. These 900 patients with rheumatic fever comprised only a minority of the cases of rheumatic fever in the army; during 1942, 1943, and 1944 there were respectively about $1,300,7,000$, and 6,000 cases of rheumatic fever which developed among soldiers in the United States and were recorded by the Surgeon-General's office. ${ }^{12}$

The policies of the War Department regarding the diagnosis and management of rheumatic fever have been outlined. ${ }^{13}$ The oral administration of salicylates was considered generally preferable to the intravenous administration. Sulphonamide chemoprophylaxis for the prevention of recurrences was approved; the drug of choice being sulphadiazine, 0.5 to $1.0 \mathrm{~g}$. daily during the period of convalescence and reconditioning, but not of course during the acute phase of the disease.

The policies of the War Department regarding disposition of such cases are flexible, not static. In general, the following patients have been discharged rather promptly from service: those with prolonged active rheumatic fever, those with frequent recurrences, and those with significant cardiac involvement. But some patients in the last category who possessed unusual technical skills or other military qualifications have been retained on limited service if their cardiac lesions were well compensated. Most of the 900 patients admitted to these three centres have been or will be returned to temporary limited duty for six months in a warm dry climate. Thereafter, re-examination and final disposition will be made. To prevent psychic invalidism, the War Department has advised that such temporary duty should not involve undue limitation of physical activity.

These three rheumatic fever centres belong to the Army Service Forces. In addition, the Army Air Forces have initiated a programme of rheumatic fever control in several of their southern regional hospitals. ${ }^{14}{ }^{15}$

\section{Relative Incidence of Rheumatic Diseases}

Because the patients sent to the rheumatism centre at the Army and Navy General Hospital are selected, our census does not reflect the relative incidence of the rheumatic diseases in the Army as a whole. An analysis of our first 1,000 cases has

TABle 2.-Incidence of Various Types of Rheumatic Diseases AMONG THE FIRST 1,000 CONSECUTIVE ADMISSIONS TO THE Rheumatism Centre, Army and Navy General Hospital

\begin{tabular}{|c|c|c|}
\hline & Cases & Percentage \\
\hline 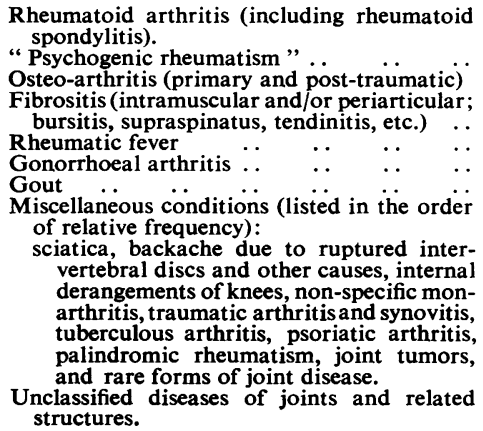 & $\begin{array}{r}331 \\
200 \\
136 \\
134 \\
22 \\
13 \\
10\end{array}$ & $\begin{array}{r}33 \cdot 1 \\
20 \cdot 0 \\
13 \cdot 6 \\
13 \cdot 4 \\
\\
2 \cdot 2 \\
1 \cdot 3 \\
1 \cdot 0 \\
\\
11 \cdot 3\end{array}$ \\
\hline Total & 1,000 & 100 \\
\hline
\end{tabular}

revealed a relative incidence as given in Table 2 . A more detailed survey is being prepared for a later report.

These figures may be compared to the incidence of rheumatic diseases as seen in a general hospital which is not a rheumatism centre. ${ }^{16} 17$ Here, as in all rheumatism clinics, rheumatoid arthritis presented the main problem; it affected one-third of all patients admitted. About one-fifth of the patients admitted as " rheumatic " had no significant organic skeletal disease. They suffered from. 
psychoneurosis manifested by musculo-skeletal symptoms, a condition called by some " psychogenic rheumatism." 17 by others "psychoneurotic rheumatism" 18 or "psychosomatic rheumatism." 19 This condition will be discussed later herein. Because of the relative youth of soldiers the incidence of gout and gouty arthritis has been low, the relative incidence being $1 \%$ as compared to a relative incidence of 4 or $5 \%$ frequently seen in civilian rheumatism clinics. Thanks to modern chemotherapy, the total and relative incidence of gonorrhoeal arthritis has been low.

About one-third of our cases of rheumatoid arthritis have been of rheumatoid spondylitis-a relative incidence surprisingly high and in notable contrast to experiences in civilian practice. For many months we have had at any given time from 70 to 100 cases of rheumatoid spondylitis at this centre. The relative frequency of such cases among soldiers probably arises from three factors: (1) rheumatoid spondylitis affects males much oftener than females, and especially affects young males of military age (18 to 30 years); (2) the early symptoms of the disease-such as vague intermittent low back pain-are difficult to evaluate, and an early diagnosis is often not made-many such early cases in young men have not been recognized until after their induction into the Army; (3) the strenuous physical exertions of Army life and training soon aggravate the symptoms and bring to light these early, previously undiagnosed, cases.

The figures on the relative incidence of rheumatic diseases as seen at our centre are, with a few exceptions, in close agreement with those from the centre at Ashburn General Hospital. Through the courtesy of the Commanding Officer and Staff of that hospital we are permitted to report the relative incidence of "rheumatic diseases" among their first 800 completed cases ${ }^{10}$ (Table 3). Thus, at

Table 3.-Incidence of " Rheumatic Diseases" at The Rheumatism Centre, Ashburn General HoSPITAL: First 800 Completed Cases

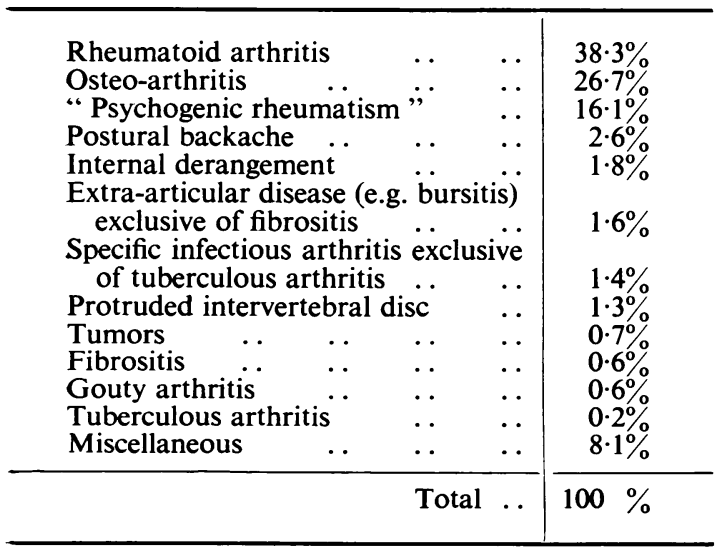

the two centres the relative incidences were: rheumatoid arthritis 33 and $38 \%$, "psychogenic rheumatism" 20 and $16 \%$, specific infectious arthritis (including gonorrhoeal and tuberculous arthritis) 1.9 and $1.6 \%$, and gouty arthritis 1.0 and $0.6 \%$.

\section{Problem of Differential Diagnosis}

So relatively inadequate was the general knowledge of the arthritides 25 years ago that a diagnosis of "acute arthritis" or of " chronic arthritis," made without further qualification, was then excusable. Thus, the articular and muscular conditions encountered in the First World War were often not clearly defined (Table 1). To-day an unqualified diagnosis of "acute arthritis" or of "chronic arthritis" is considered inadequate except in rare instances. Although there are many types of acute and chronic arthritis, the rheumatologist and the interested internist should be able usually to sub-divide them and state what kind of " chronic arthritis" is present. This is a matter of considerable importance in treatment, but it is especially important for a proper estimate regarding prognosis and military disposition.

An analysis of the transfer diagnoses-those with which the patients arrived at the centre-has revealed scores of patients sent here for "arthritis" who had no arthritis at all. Many patients presumed to have "osteo-arthritis" actually had rheumatoid arthritis, and vice versa. Few of the cases of gout had been correctly diagnosed. A great many of the patients with " muscular rheumatism" actually had, not myositis or fibrositis, but "psychogenic rheumatism"-psychoneurosis manifested by musculo-skeletal complaints. Such errors in diagnosis are no particular reflection on medical officers. They merely reflect the diagnostic level of the medical profession as a whole in matters rheumatologic, and exhibit once more the need of physicians in general for a wider and more critical knowledge of fundamentals in the diagnosis of diseases of joints.

\section{Gonorrhoeal Arthritis and Arthritis Aggravated by Gonorrhoea}

It is not sufficiently understood that rheumatoid arthritis can be precipitated by a gonorrhoeal infection, just as it can be precipitated by tonsillitis, influenza, or some other acute infection. Also a mild, intermittent, or quiescent rheumatoid arthritis can be aggravated by acute genital gonorrhoea. Such cases have sometimes been called "postgonorrhoeal rheumatoid arthritis," but this condition does not represent chronic rheumatoid arthritis engrafted on, or evolving from, a subsiding acute gonorrhoeal arthritis; it represents simply rheumatoid arthritis precipitated or aggravated by acute genital (not articular) gonorrhoea. This entity is not new to the experienced rheumatologist. It is regularly encountered in civilian practice, and in $1 \%$ of Pemberton's cases of chronic arthritis among soldiers in the last World War the arthritis began in close relation with the onset of gonorrhoea. ${ }^{4}$ Proven gonorrhoeal arthritis among American soldiers in this war appears to be rather rare. In 
this rheumatism centre we have seen many more cases of rheumatoid arthritis precipitated or aggravated by gonorrhoea than of gonorrhoeal arthritis. Most of the former cases have been erroneously labelled gonorrhoeal arthritis, treated as such unsuccessfully by sulphonamides or penicillin or by fever therapy, and transferred to our centre labelled "gonorrhoeal arthritis resistant to penicillin and/or sulphonamides." In our experience, most cases of so-called " gonorrhoeal arthritis resistant to chemotherapy" have turned outas shown by their subsequent course, therapeutic tests and, in some cases, articular biopsies - to be cases of rheumatoid arthritis. ${ }^{20}$ This matter will be the subject of a later report.

\section{" Psychogenic Rheumatism"}

Physicians in general are familiar with psychoneurosis as it may affect the gastro-intestinal tract (functional dyspepsia, neurasthenia gastrica, irritable colon, anorexia nervosa, etc.) or the cardiovascular system (cardiac neurosis, soldier's heart, neurocirculatory asthenia). Physicians are not so familiar with psychoneurosis as it affects the locomotor system. "Psychogenic rheumatism"-the musculo-skeletal expression of functional disorders, tension states, or psychoneurosis - is one of the commonest causes of generalized or localized aches and pains in muscles and/or joints in either civilian or military life. It may exist alone, or may occur as a functional overlay of some rheumatic disease such as fibrositis or rheumatoid arthritis. The designation "psychoneurosis manifested by musculoskeletal complaints" is more proper than the terms "psychogenic rheumatism" or "psychosomatic rheumatism." But the term " psychogenic rheumatism" persists in token of its compactness and handiness; if its limitations are understood it can be a useful label.

Many inadequate, unadaptive soldiers unconsciously make "flight into illness" via musculoskeletal complaints which they, and some physicians also, erroneously call " rheumatism " or " arthritis." These patients have many symptoms but no objective, constitutional, röntgenographic or biochemical manifestations of disease. Actually these patients have no real " rheumatism," no true synovitis, arthritis, or organic muscular lesion; or, if some minor musculo-skeletal disease does coexist, it is insufficient to account for the severity of the disability. The clinical pattern is not that of organic rheumatic disease. Typical functional complaints referable to other systems often may be elicited. The degree of psychoneurosis present may vary from a mild anxiety tension state to a major conversion hysteria; camptocormia (hysterical bent back), bizarre gaits, peculiar articular postures, or hysterical flexed fingers are not uncommon. It will be noted that about $20 \%$ of our patients and about $16 \%$ of those admitted to the centre at Ashburn General Hospital had no significant organic rheumatic disease, at least by the time they reached the centres (Tables 2 and 3). They either had "psychogenic rheumatism " alone, having had no organic " rheumatic disease" at all, or they had a dominating " psychogenic rheumatism " which completely overshadowed an initial and still underlying mild fibrositis or arthritis, or which had completely replaced a previous rheumatic disease (e.g. fibrositis or rheumatic fever), no longer active.

The prompt recognition of " psychogenic rheumatism" is of great importance in the Army to prevent the continuation of the disorder to the point of irreversibility, to prevent unnecessary and unjustified discharge of men on life-time pensions for non-existent " arthritis" or " fibrositis," and, above all, in order to institute the proper methods for the physical and psychic rehabilitation of these unfortunate and generally misunderstood patients.

Differentiation of " Psychogenic Rheumatism" FROM FIBROSITIS

Primary fibrositis is the chief rheumatic disease from which "psychogenic rheumatism" must be differentiated. In general, primary fibrositis puts its victims at the mercy of changes in external environment: thus weather, heat, cold, humidity, rest, exercise, etc., characteristically influence most of them for better or for worse. On the other hand, "psychogenic rheumatism" generally puts its victims at the mercy of changes in internal environment: thus their symptoms may vary with mood or psyche, pleasure, excitement, mental distraction, worry, or fatigue. Space does not permit the inclusion here of more than a tabular differentiation in general terms (Table 4). The differentiation depends, of course, not on any one feature, but on a combination of features. When a case of one or the other disorder is relatively " pure," differentiation is readily made. Differentiation and a correct assay of the problem are especially difficult when a mild fibrositis coexists with a marked functional overlay. Nevertheless, this differentiation has been very useful to us.

\section{Treatment}

The comprehensive schemes of treatment used at this centre for the various rheumatic diseases are those approved by the American Rheumatism Association ${ }^{21}$ and used by the leading rheumatologists of the country. This centre does have unusual facilities for physical therapy and hydrotherapy; these facilities are used properly, but without undue emphasis, and certainly not to the exclusion of any other useful measure.

Group lectures.-Rheumatic victims are, in general, docile, patient, and well-behaved. Of their physicians they ask surprisingly little; in lieu of the elusive " rapid-cure," they ask only for a diagnosis and a decent understanding of what they are up against, what they can do to help themselves, and what they should not do lest they make themselves worse. They will abandon the physician who brushes them off with an incomplete diagnosis or a fancy diagnosis in medical terms and "a few well chosen words." To answer their need, we have instituted here a regular rotating series of 
Table 4.-Tabular Differentiation between Fibrositis and "Psychogenic Rheumatism"

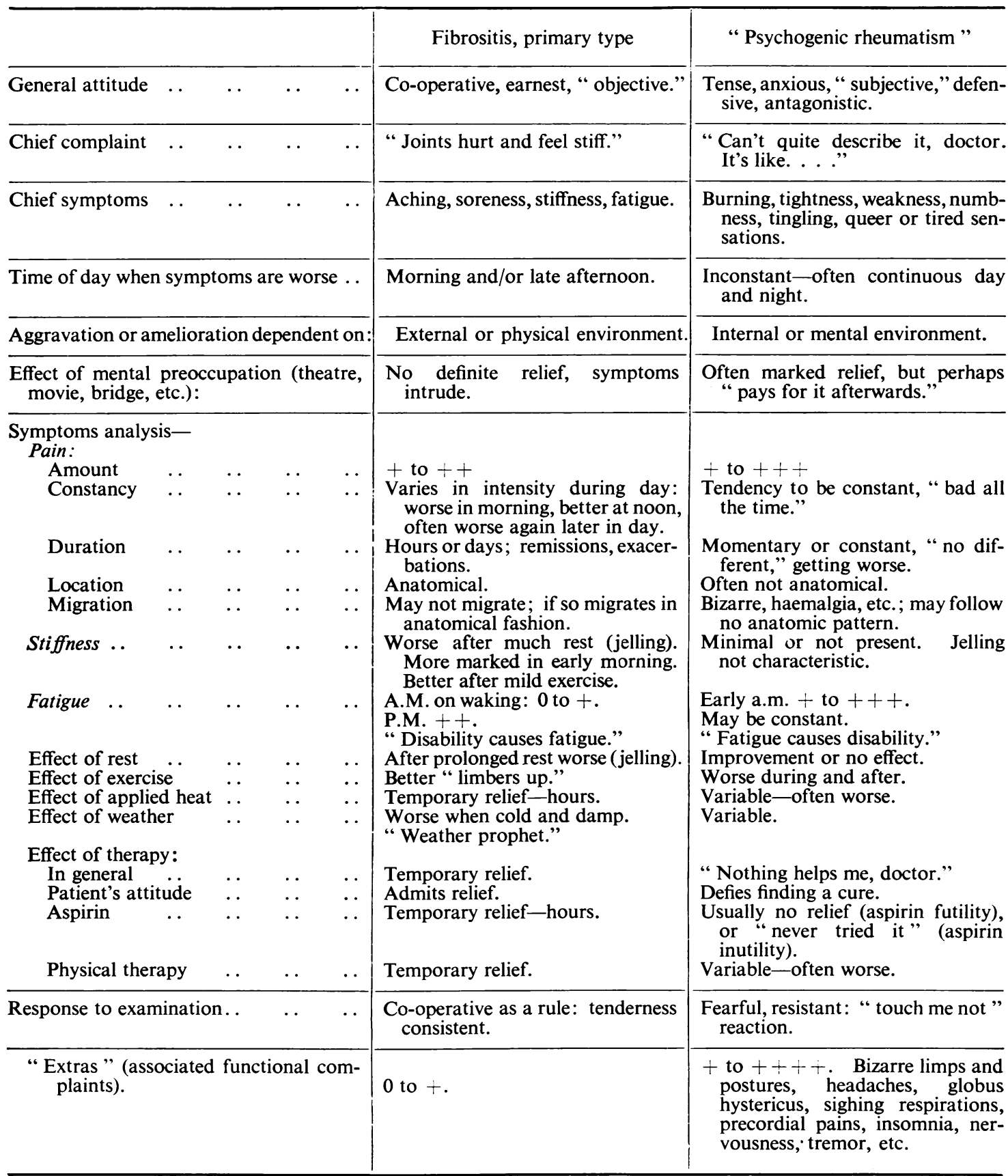

group consultations or " lectures on rheumatism" given in laymen's language. Of the twelve different lectures, two or three are on general topics for all patients; others are given to the appropriate groups of (generally 25 to 100) patients with a particular disease. One group of patients is usually not admitted to the specific lectures designed for another group. Patients with " psychogenic rheumatism" especially are not permitted to attend the lectures for patients with rheumatoid arthritis or fibrositis, lest misinterpretations arise. Instead, those with "psychogenic rheumatism" hear special talks designed for their particular needs and given jointly by a rheumatologist and psychiatrist.

The lectures are on the following subjects: (1) the meaning of rheumatism and arthritis; (2) facts, fads, and false concepts about rheumatism; (3) fibrositis-its meaning and management; (4) rheumatoid arthritis and its management; (5) rheumatoid spondylitis and its management; (6) facts about osteo-arthritis; (7) gout and gouty arthritis; (8) shoulder disabilities and their management; (9) body mechanics in relation to disability of joints; (10) home physical therapy (motion picture and 
demonstration); (11) emotional tension and its relation to "rheumatism"; (12) the management of rheumatic fever.

These group consultations are not a substitute for, but supplemental to, individualized consultations. These are designed to project beyond the period of Army hospitalization and into the patient's home at least some of the benefits he may derive from the more formal treatments here. They also serve as an introduction to the advice which each patient will later receive from his home physician. The lectures have been well received, and, incidentally, have been a great time-saver for the busy medical officer. After each lecture the patients are encouraged to ask questions on points that bother them, no matter how trivial they may seem; any question about something not understood is a valid question. The lectures also improve morale: seeing that he is not alone in his problem and that others are worse than he, the patient takes courage.

Rheumatoid arthritis.-Our treatment for this disease is quite standard, and includes the removal of obviously infected foci, the use of highly nutritious diets (but there is no "anti-rheumatism vitamin" or specific diet), foreign protein therapy in selected cases, simple analgesics, physical therapy, occupational therapy, orthopaedic measures to prevent or correct deformities, gold salts carefully administered to selected patients whose rheumatoid arthritis is progressive in spite of more conservative measures, and röntgen therapy for certain cases of rheumatoid spondylitis. We found penicillin to be ineffective. ${ }^{22}$

Psychogenic rheumatism.-The treatment of psychogenic rheumatism has been an interesting but difficult problem, second here in importance only to that of the treatment of rheumatoid arthritis. Our pleasure at being able to reassure soldiers with psychogenic rheumatism that they do not have arthritis or muscular rheumatism and that they need not fear the presence of a crippling disease is tempered by the difficulty of helping them to develop insight and to accept their diagnosis, at least to the point of submitting whole-heartedly to a trial of psychotherapeutic reconditioning. In these cases the latter is of much greater value than physical reconditioning; physical reconditioning used alone in these cases accomplishes little or nothing. Patients with psychogenic rheumatism are not generally given formal courses of physical therapy or other treatments used for "organic rheumatism" except as diagnostic or therapeutic tests, because such treatments often tend to fix more firmly in their consciousness the belief that they have organic disease.

\section{The Rheumatic Soldier's Future}

Nothing could destroy a soldier's potentialities for salvage (his morale, his will to recover and to serve) more readily than the atmosphere of a " chronic hospital," a " rheumatic old soldier's home." The rheumatic soldier should not be kept in a state of proionged uncertainty as to whether he will probably be returned to duty (limited duty, if necessary) or whether he will be discharged from the Army. Whatever his future is to be, it should be, relatively speaking, an immediate future, not a vague distant future. No hasty dispositions should be made, but in most cases it does not take long to determine the probable disposition required for a given rheumatic disease or the future military potentialities of a given rheumatic soldier. Furthermore, " right or wrong," a disposition should be made fairly promptly, unless prolonged definitive treatment is indicated; otherwise the rheumatic soldier may develop the hospital habit, the outlook of the dependent chronic invalid or pensioner. If hospitalized too long, a salvageable patient with a mild form of rheumatism may, even though he was originally well orientated, develop some form of hospital-engendered psychoneurosis or fixation of illness, and the functional overlay may become more difficult to treat than the original organic disease upon which it became superimposed. To combat these possibilities, each patient on arrival is told that his stay is decidedly not indefinite, and that his period of hospitalization will follow a rather definite and progressive, though elastic, schedule: a few days for a thorough initial physical survey, then a period of intensive treatment (generally about 3 to 8 weeks, longer in selected cases), after which it will be decided whether he can be " reconditioned " for further military service or should be " rehabilitated" for civilian life.

Reconditioning.-Getting a convalescent soldier physically and mentally prepared to return to military duty is spoken of as " reconditioning." ${ }^{23}$ The salvageable rheumatic soldier is "reconditioned," first in the hospital by the medical programme noted above, then by a supplemental period of two or more weeks during which time he lives in a convalescent barracks and undergoes daily a programme of physical activity carefully measured to his abilities. Some patients recovering from a transient rheumatic disease can participate in a fairly strenuous programme; for other patients, who at best can only be expected to return to limited service, the reconditioning programme is less strenuous; in every instance an attempt is made to apply the programme as an individual prescription.

Rehabilitation.-If a soldier's rheumatism precludes the possibility of his return to duty within a reasonable period of time, if his disease is essentially progressive and disabling, the soldier will be made ready for discharge to civilian life and for subsequent follow-up treatments by his civilian physician or, if necessary, by a Veterans' Hospital. To such a soldier, as to the one who can return to duty, the Army acknowledges an equal obligation: getting him prepared mentally and physically to return to a useful civilian life, despite his rheumatic disability, is spoken of as " rehabilitation."

After his discharge from the Army the arthritic patient may have to modify the pattern of his life somewhat, so as to avoid factors known to be aggravating to his disease. But he must not alter 
his life to the point of engendering defeatism. The educational programme mentioned heretofore is one of our chief weapons against the dangers of a wheel-chair or crutch psychology. The discharged arthritic patient must still regard himself as a vital unit of his community. We, therefore, attempt to teach him how to live with his disease, not for it. As long as possible, the treatment of his rheumatism should be merely an avocation, not his vocation. If, prematurely or needlessly, he makes a vocation of his disease, he has taken a long step toward the sterile existence of the pensioner's rocking chair.

Policies.-Each of the rheumatic diseases poses its own problem in disposition. For patients recovering from acute rheumatic fever the disposition must take into account the presence or absence of rheumatic carditis or the likelihood of its early development. The need for manpower has been such that blanket discharges for rheumatic fever could not be entertained. Dispositions have been individualized. ${ }^{13}$ The general policy in force at the rheumatic fever centres has been mentioned.

Most patients with rheumatoid arthritis, certainly those with progressive disease, should be discharged. However, we have attempted to salvage the mildly affected patients whenever possible; otherwise we cannot learn to what extent salvage is feasible or to what extent the Army can utilize the soldier with a clear brain and stout heart, but with slightly rheumatic joints.

The disposition of patients with "psychogenic rheumatism" requires individual consideration. Many soldiers affected with psychoneurosis of mild or moderate degree can still render effective service. But we are ordered to conserve, not men, but manpower. When, despite conscientious treatment, "psychogenic rheumatism" persists to the extent that its victim no longer represents a unit of manpower, then he is recommended for discharge, because a man without power is a drag on the Army.

\section{Statistics on Disposal}

For this report we have summarized the methods of disposal in 1,300 cases, not chosen serially, but selected only so as to include a representative number of cases of each of the commoner rheumatic diseases (Table 5). Of the 1,300 patients, 589 (or $45.3 \%$ ) were returned to duty of some kind, to full duty or to temporary or permanent limited duty; 711 (or $54.7 \%$ ) were discharged (enlisted men) or retired (officers) from service. Thus about half of the patients were returned for a further trial of duty. In contemplating these preliminary results one must keep in mind the fact that military duty, even limited duty, is pretty strenuous business, unsuited for those who cannot work regularly at least eight hours a day. The concessions that can be made to the rheumatic soldier are limited.

A follow-up study is being made of both groups: of the retained group to note to what extent our attempts at salvage were successful; of the dis-
Table 5-Disposition of 1,300 Soldiers with Rheumatic Disease AT THE RHEUmatism Centre, ARMY aND NAVY General HOSPITAL

\begin{tabular}{|c|c|c|c|c|c|}
\hline \multirow[t]{2}{*}{ Condition } & \multirow[t]{2}{*}{ Patients } & \multicolumn{2}{|c|}{$\begin{array}{l}\text { Returned to } \\
\text { duty (full or } \\
\text { limited duty). }\end{array}$} & \multicolumn{2}{|c|}{$\begin{array}{l}\text { Separated from } \\
\text { Service by } \\
\text { medical dis- } \\
\text { charge or re- } \\
\text { tirement. }\end{array}$} \\
\hline & & Patients & $\%$ & Patients & $\%$ \\
\hline $\begin{array}{l}\text { Rheumatoid arthritis, in- } \\
\text { cluding rheumatoid } \\
\text { spondylitis. }\end{array}$ & 500 & 76 & $15 \cdot 2$ & 424 & $84 \cdot 8$ \\
\hline $\begin{array}{l}\text { "Psychogenic rheuma- } \\
\text { tism." }\end{array}$ & 200 & 128 & $64 \cdot 0$ & 72 & $36 \cdot 0$ \\
\hline Fibrositis, primary & 150 & 123 & $82 \cdot 0$ & 27 & $18 \cdot 0$ \\
\hline Osteo-arthritis .. & 100 & 38 & $38 \cdot 0$ & 62 & $62 \cdot 0$ \\
\hline Rheumatic fever.. & 50 & 39 & $78 \cdot 0$ & 11 & $22 \cdot 0$ \\
\hline Gonorrhoeal arthritis ... & 20 & 13 & $65 \cdot 0$ & 7 & $35 \cdot 0$ \\
\hline Gout $\quad \ldots$ & 10 & 1 & $10 \cdot 0$ & 9 & $90 \cdot 0$ \\
\hline $\begin{array}{l}\text { Miscellaneous and un- } \\
\text { classified cases of arth- } \\
\text { ritis and " rheumatism." }\end{array}$ & 270 & 171 & 63.4 & 99 & $36 \cdot 6$ \\
\hline Total & 1,300 & $\begin{array}{l}589 \mathrm{pa} \\
=45\end{array}$ & $\begin{array}{l}\text { ents } \\
\%\end{array}$ & $\begin{array}{l}711 \mathrm{p} \\
=5\end{array}$ & nts \\
\hline
\end{tabular}

charged group to note the further course of the disease when the patients were freed from the physical and psychic stresses of Army life.

It will be noted that most of the patients with primary fibrositis, "psychogenic rheumatism," rheumatic fever, or gonorrhoeal arthritis were returned to duty, whereas the majority of those with rheumatoid arthritis, osteo-arthritis, or gout were separated from service. Many of our osteoarthritic patients were elderly commissioned or non-commissioned officers of long service in the Army. In our opinion most gouty patients are not suitable for Army life, considering the difficulties of following a medicinal and dietary regime and the likelihood of encountering provocative physical trauma. Frequent recurrences of acute gouty arthritis make such persons of limited or doubtful military value.

\section{Clinical Investigation}

"It is hoped to make this hospital a source of extensive knowledge on arthritis for the whole medical profession. Studies will be carried on in the use of special drugs, such as sulphonamides and penicillin, in the treatment of arthritis": so read the War Department's announcement of the establishment of the first rheumatism centre. Thus the Army acknowledged an obligation to the arthritic soldier, not merely as an individual, but as a representative of all his kind. Thus the medical officers serving at the five rheumatism centres are encouraged to improve our clinical knowledge of the rheumatic diseases, to improve, if possible, our methods of treatment, and to present clearly the results to the medical profession. In an effort to fulfill this obligation a number of clinical investigations are being carried out at each of the five centres. Although quite young, the two centres for chronic 
rheumatic disease are already, so far as we know, the largest rheumatism centres in the world. As treatment centres and carefully supervised schools of rheumatology, they are providing a unique opportunity which should benefit mutually both the rheumatic soldier and his medical officer.

\section{Summary}

"While arthritis does not account for a large percentage of illnesses in the United States Army, it has been found to be one of the most disabling ": so the War Department has stated. ${ }^{7}$ During the First World War about 93,000 American soldiers developed some type of " rheumatism," an incidence rate of 22.4 per 1,000 soldiers. The incidence of rheumatic diseases among soldiers in this, the Second World War, has been such that the Surgeon-General has established five rheumatism centres for selected cases: two for chronic rheumatic diseases, and three for rheumatic fever.

The management of rheumatic soldiers at one of the centres has been outlined. Rheumatoid arthritis, psychoneurosis manifested by musculo-skeletal symptoms (" psychogenic rheumatism "), primary fibrositis, and osteo-arthritis, were the conditions most often encountered. The high relative frequency of rheumatoid spondylitis and of " psychogenic rheumatism" were of special interest. Gonorrhoeal arthritis among soldiers appears to be relatively uncommon: cases of rheumatoid arthritis precipitated or aggravated by acute genital (not articular) gonorrhoea were more often seen. It is believed that many, if not most, cases of so-called gonorrhoeal arthritis resistant to sulphonamides and/or penicillin are in reality cases of rheumatoid arthritis precipitated or aggravated by, or coincident with, an otherwise unrelated genital gonorrhoea.

Psychoneurosis manifested by musculo-skeletal symptoms, "psychogenic rheumatism," has presented a common and difficult problem and affected 15 to $20 \%$ of the soldiers, presumably " rheumatic," admitted to the two centres for chronic rheumatism. The recognition of "psychogenic rheumatism" is of importance in military life in order to initiate effective treatment promptly and to prevent unnecessary discharges and pensions for non-existent " arthritis " or " muscular rheumatism." Psychogenic rheumatism must be differentiated, especially from primary fibrositis (muscular or capsular rheumatism). In general, fibrositis puts its victims at the mercy of changes in external environment (weather, heat, cold, humidity, rest, exercise) whereas "psychogenic rheumatism" tends to put its victims at the mercy of changes in internal environment, symptoms being altered for better or worse by changes of mood or psyche, by pleasure, excitement, mental distractions, worry, or fatigue. The clinical differentiation has been outlined briefly.

Of 1,300 "rheumatic patients" disposed of at one of the centres for chronic rheumatism, $45 \%$ were returned to some type of military duty; $55 \%$ were discharged from Service.

The five rheumatism centres are providing an unusual opportunity to give the rheumatic soldier the best available study and treatment and to advance the knowledge of rheumatic diseases.

\section{REFERENCES}

1. The Medical Department of the United States Army in the World War. Vol. XV, statistics. Part Two-Medical and casualty statistics based on the medical records of the United States Army, April 1, 1917, to Dec. 31, 1919, inclusive. Prepared under the direction of Major-General M. W. Ireland, The Surgeon-General, by Major Albert G. Love, M.C., U.S. Army. Washington. Government Printing Office. 1925. (See pp. 86, 90, 94, 102, 110,114, 126, 582.

2. Matz, P. B. (1933). New Engl. J. Med., 209, 547, 597, 639.

3. Personal communication from the Veterans' Administration, Washington, D.C.

4. Pemberton, Ralph, Buckman, T. E., Foster, G. L., Robertson, J. W., and Tompkins, E. H. (1920). Arch. intern. Med., 25 231, 335.

5. Personal communication from Dr. Ralph Pemberton.

6. Hench, P. S., Osgood, R. B., and Wainwright, C. W. (1942) Army Med. Bull., 60, 1.

7. Centre for Treatment of Arthritis (1944), Bull. U.S. Army med. Dept., 77, 20 ; and J. Amer. med. Ass., 124, 991.

8. War Department Headquarters Army Service Forces. Washington (Letter SPX 705-23, Nov. 1943) Dec. 17, 1943 ; Genera Hospitals designated for specialized treatment.

9. War Department Cicular No. 347, Washington, D.C., Aug. 25, 1944

10. Personal communications from Col. J. B. Anderson, Lt.-Col. John Harvey, Major David Kydd, and Lt. Charles W. Fogarty. Jr., Ashburn General Hospital.

11. Personal communications from Col. A. C. Miller and Lt.-Col. J. D. Davis, Birmingham General Hospital; Col. D. C. Campbell and Lt.-Col. L. S. Faust, Foster General Hospital and Col. A. B. Jones, Torney General Hospital.

12. Weekly Health Reports and additional data from Army Service Forces. Office of the Surgeon-General, Medical Statistics Division.

13. War Dept. Army Service Forces, Office of the Surgeon-General, Aug. 7, 1943, Circular Letter No. 144; War Dept. Army Air Force Letter 25-7, April 29, 1944: War Department Technical Bulletin 97, Rheumatic Fever, Washington, D.C., Sept. 29, 1944.

14. Holbrook, W. Paul (1944). J. Amer. med. Ass., 126, 84

15. News Letter, published monthly by the Army Air Force Rheumatic Fever Control Programme-Maj. C. A. R. Connor, Editor; available from the Josiah Macy Jr. Foundation, New York City.

16. Boland, E. W. (1944). California and Western Med., 60, 7.

17. Boland, E. W., and Corr, W. P. (1943). J. Amer, med. Ass., 123,805 .

18. Halliday, J. L. (1937). Brit. med. J., 1, 213, 264.

19. Halliday, J. L. (1941) Ann intern Med., 15, 666

20. Hench P. S., quoted by Herrell, W. E., "Penicillin and Other Antibiotic Agents." W. B. Saunders Co., Philadelphia and Antibiotic Agents."
London, 1945, pp. 348.

21. Hench, P. S., Bauer, Walter, Boland, E. W., Dawson, M. H., Freyberg, R. H., Holbrook, W. P., Key, J. A., Lockie, L. M., and McEwen, Currier. (1941). Ann, intern. Med. 15, 1002.

22. Boland, E. W., Headley, N. E., and Hench, P. S. (1944). J. Amer. med. Ass., 126, 820 .

med. Ass., 126, 820.
23. Hillman, C. C. (1944). Milit. Rev., 24, 10. 